\title{
O Direito Sanitário no Brasil: um panorama do ensino especializado e sua práxis restrita
}

Health Law in Brazil: an overview of the specialized tutorship and its strict praxis

La Ley de Salud en Brasil: una visión general de la enseñanza especializada y su práctica restringida

\section{Marliete Ferreira do Amaral ${ }^{1}$}

Resumo: O direito universal à saúde, garantido no Brasil pela Constituição Federal, não tem sido assegurado, na prática, aos cidadãos brasileiros em geral. Essa realidade reveste de importância decisiva o que veio a ser conhecido como Direito Sanitário. Assentado principalmente nas ciências do direito e da saúde, mas pleno de contribuições da sociologia, da antropologia e de outras ciências sociais, o Direito Sanitário trata fundamentalmente de questões relacionadas às demandas e aos problemas de saúde pública da população. A complexidade e a multiplicidade de situações envolvendo a garantia desse direito fundamental do cidadão tornam o ensino do Direito Sanitário e a formação de profissionais especializados imperiosa necessidade, juntamente com outras ações. Pesquisa realizada junto a universidades públicas federais e a outras instituições de ensino e pesquisa no Brasil constatou, no entanto, que o ensino especializado do Direito Sanitário está restrito a algumas poucas instituições e inexiste em cursos de pós-graduação em todas as universidades públicas federais. $O$ estudo revelou, ainda, que mesmo nas instituições onde o ensino especializado é assegurado regularmente, ele não integra o programa curricular de cursos de direito, mas de cursos sobre saúde. O trabalho concluiu que a ampliação da oferta de cursos de capacitação e especialização em Direito Sanitário é indispensável para alargar as conquistas do direito à saúde.

Palavras-chaves: Direito Sanitário, Direito à saúde, Ensino do Direito Sanitário

\begin{abstract}
The universal right to health, guaranteed in Brazil by the Federal Constitution, has not been ensured to Brazilian citizens in general. This reality covers with crucial importance what has come to be known as Health Law. Defined primarily on the basis of law and health sciences, but also full of contributions from sociology, anthropology and other social sciences, Health Law fundamentally responds to issues related to the population's public health demands and problems. The complexity and the multiplicity of cases involving the maintenance of this primordial right make the teaching of Health Law and the training of specialized professionals, along with other actions, an imperious need. A research endeavored by federal public universities and other educational and research institutions in Brazil found, although, that the specialized teaching of Health Law is restricted to a few institutions and it is nonexistent in postgraduate courses at all federal public universities. The study also revealed that even in institutions where specialized instruction is provided regularly, it is not part of the curriculum of law courses, but courses on health. The study concludes that the expansion of the offering of training and specialization courses in Health Law is indispensable to extend the achievements of the health rights.
\end{abstract}

\footnotetext{
${ }^{1}$ Advogada, especialista em Direito Penal e Direito Processual Penal pela Universidade Cândido Mendes/Rio de Janeiro e doutoranda em Ciências Jurídicas e Sociais na Universidad del Museo Social Argentino (UMSA). Assessora do Governo do Estado do Amazonas.

E-mail: marlieteamaral@hotmail.com
} 
Keywords: Health law, Health law teaching.

Resumen: El derecho universal a la salud, garantizado en el Brasil por la Constitución Federal, no ha sido asegurado en la práctica a los ciudadanos brasileños en general. Esa realidad cobre de importancia decisiva al que vino a ser reconocido como Derecho Sanitario. Fundamentado principalmente en las Ciencias del Derecho y de la Salud, mas lleno de contribuciones de la sociología, de la antropología y de otras ciencias sociales, el Derecho Sanitario trata fundamentalmente de cuestiones relacionadas a las demandas y a los problemas de salud pública de la población. La complejidad y la multiplicidad de situaciones envolviendo la garantía de ese derecho fundamental del ciudadano tornan la enseñanza del Derecho Sanitario y la formación de profesionales especializados imperiosa necesidad, juntamente con otras acciones. La investigación realizada junto a las universidades públicas federales y otras instituciones de enseñanza e investigación en Brasil constató, sin embargo, que la enseñanza especializada del Derecho Sanitario está restricta a algunas pocas instituciones e es inexiste en cursos de posgrado en todas las universidades públicas federales. El estudio reveló aún que mismo en las instituciones donde la enseñanza especializada es asegurada regularmente, él no integra el programa circular de los cursos de derecho, pero de curso sobre salud. En esto trabajo se concluí que la ampliación de la oferta de cursos de capacitación e especialización en Derecho Sanitario es indispensable para ampliar las conquistas del derecho a la salud.

Palabras clave: Derecho Sanitario, Derecho de la salud, Enseñanza del derecho de la salud

\section{Introdução}

\section{O direito à saúde na Constituição Federal de 1988}

A Constituição da República Federativa do Brasil, em especial no seu art. 196, expressa:

Art. 196. A saúde é direito de todos e dever do Estado, garantido mediante políticas sociais e econômicas que visem à redução do risco de doença e de outros agravos e ao acesso universal e igualitário às ações e serviços para sua promoção, proteção e recuperação. (1)

O art. 23, inciso II, da Carta Magna, que estabelece como competência comum dos entes federativos 'cuidar da saúde', e o art. 24, inciso XII, que inclui no âmbito da competência concorrente a legislação sobre 'proteção e defesa da saúde' são dispositivos que igualmente impõem deveres e obrigações ao Estado.

O direito à saúde é, portanto, um direito público que vincula o Estado ao dever de legislar e desenvolver políticas públicas que venham a garantir esse direito. 
A previsão constitucional do direito à saúde transforma o que poderiam ser meros programas políticos de incentivo social, em direito material de caráter obrigatório e de aplicação imediata.

Já o $\S 1^{\circ}$ do art. $5^{\circ}$ da CF de 1988, estabelece que "as normas definidoras dos direitos e garantias fundamentais tem aplicação imediata" e confirma, assim, a importância que o Estado deve dar ao direito à saúde do cidadão.

\section{O Direito Sanitário na Constituição}

O Direito Sanitário insere-se no contexto da Constituição por meio de seus princípios. Dentre eles estão os que regem os princípios gerais da ordem social (art. 193), os da seguridade social (art. 194) e os que regem a saúde (arts. 196 e 198). A análise desses dispositivos demonstra a efetividade com a qual o Governo deve agir na prestação e no desenvolvimento das políticas públicas, com limites impostos a discricionariedade de seus atos.

Para respaldar o preceito constitucional, o art. 198, criou o Sistema Único de Saúde, regulado pelas chamadas Leis Orgânicas da Saúde (LOS) que são leis que detalham a organização e o funcionamento do novo sistema de saúde estabelecido pela Constituição Federal.

A Lei $n^{\circ} 8.080$, de 19/9/1990, dispõe sobre as condições para a promoção, proteção e recuperação da saúde, a organização e o funcionamento dos serviços correspondentes, e dá outras providências. Já a Lei $n^{\circ}$ 8.142, de 28/12/1990, dispõe sobre a participação da comunidade na gestão do Sistema Único de Saúde (SUS) e sobre as transferências intergovernamentais de recursos financeiros na área da saúde, e dá outras providências.

Pode-se dizer que a normatização desse direito ainda não está devidamente consolidada, em razão da multiplicidade de aspectos e fatores condicionantes a envolver o tema. A Lei $\mathrm{n}^{\circ}$ 8.080, de 1990, em seu art. 3º estabelece que a saúde tem como "determinantes e condicionantes, entre outros, a alimentação, a moradia, o saneamento básico, o meio ambiente, o trabalho, a renda, a educação, a atividade física, o transporte, o lazer e o acesso a bens e serviços essenciais" (2).

Cabe, desta forma, admitir que a Constituição Federal de 1988 instituiu efetivamente, embora não textualmente, o Direito Sanitário, como um novo ramo do Direito 
no Brasil. Desde então, a população brasileira, em geral, bem como os estudiosos e os operadores da saúde e do direito, além dos legisladores, buscam o entendimento capaz de definir, regulamentar e ampliar essa conquista.

\section{Panorama do ensino especializado do Direito Sanitário no Brasil}

De fundamental relevância mapear o ensino do Direito Sanitário nas instituições brasileiras. Discute-se a melhor formatação e implementação da grade curricular e transmissão do conhecimento na área do Direito Sanitário no País, a fim de capacitar e de preparar, adequadamente, profissionais para atuarem nesse segmento.

São poucas as instituições, concentradas principalmente na região Sudeste, que oferecem cursos regulares desse ramo de conhecimento. E, de modo geral, os cursos de Direito Sanitário estão inseridos na área de saúde pública e não na área do direito.

Em decorrência disso, infindáveis são as discussões sobre o conceito do tema, quais os seus domínios e como deve ser difundido.

De acordo com Dallari (3), o Direito Sanitário é um ramo do direito que: [...]

[...] se interessa tanto pelo direito à saúde, enquanto reivindicação de um direito humano, quanto pelo direito da saúde pública: um conjunto de normas jurídicas que têm por objeto a promoção, prevenção e recuperação da saúde de todos os indivíduos que compõem o povo de determinado Estado, compreendendo, portanto, ambos os ramos tradicionais em que se convencionou dividir o direito: o público e o privado.

Canut (4) conceitua o Direito Sanitário, resumidamente, como o ramo do direito destinado à proteção do direito à saúde - em seu sentido mais amplo - por meio de normas e princípios específicos.

Para Delduque (5),

El Derecho Sanitario es, sin embargo, una rama del conocimiento con autonomía científica. Es una disciplina sui generis porque las reflexiones pueden ser de pura teoría jurídica, de filosofía jurídica, como también investigaciones con resultados de calidad y cantidad, como en lo empirismo. El Derecho Sanitario es parte del Derecho Público.

El Derecho Sanitario es el resultado no de la necesidad de regulación jurídica de una actividad económica o profesional, sino del reconocimiento de la salud como fenómeno y proceso social y como derecho fundamental - y como tal de relevancia pública. 
O Direito Sanitário no Brasil, como estabelecido na Constituição brasileira, está intrinsecamente relacionado com o direito à saúde e é de relevância pública. Ele é operacional no âmbito das instituições públicas, a partir do ordenamento jurídico e sanitário existente, com o fim de melhorar as condições de saúde da população.

Aith et al. (6) afirmam que a Constituição brasileira, ao reconhecer a saúde como um direito humano fundamental, consolida o Direito Sanitário, que deve contar com regime jurídico específico que vise à efetivação do direito à saúde. O autor acrescenta que deve ser compreendido como o ramo do direito que disciplina as ações e serviços públicos e privados de interesse da saúde.

O Direito Sanitário, ainda de acordo com Aith et al. (6), guarda relação com outros ramos do direito, uma vez que aponta em sua evolução no sentido de definir, com a maior precisão possível, o conceito jurídico de saúde, pois somente essa resposta poderá oferecer os contornos jurídicos da saúde como um direito fundamental e determinar a amplitude dos deveres do Estado para a efetivação desse direito.

De igual forma, Dias (7) entende que o Direito Sanitário guarda relação com outros ramos do direito: i) com o direito constitucional, pelo próprio preceito que define as competências e responsabilidades dos poderes públicos, inclusive na fiscalização das iniciativas privadas; ii) com o direito do trabalho, pela íntima preocupação com as medidas de proteção e recuperação da saúde dos trabalhadores e de segurança do trabalho; iii) com o direito penal, dados os princípios e normas jurídicas a coibir e reprimir as infrações e delitos contra a saúde pública; iv) com o direito processual, pelo emprego da legislação na apuração de infrações à saúde e atos administrativos correlatos; e v) com o direito internacional público, seja pelas normas estabelecidas em tratados, acordos, convenções e regulamentos sanitários diretamente com países, seja pela subscrição de acordos multilaterais referentes à saúde regidos pelo direito internacional, como a Declaração Universal dos Direitos do Homem, a Convenção Pan-Americana de Direitos do Homem, a Convenção Internacional Sobre Todas as Formas de Discriminação Racial e outras.

Sobre essa interdisciplinaridade, Aith (8) explica que se trata de "fenômeno comum na área do direito, pois diferentes ramos especializados da ciência jurídica se cruzam, se interpenetram e se relacionam entre si para uma aplicação mais adequada do Direito, que faça jus à complexidade social". 
O amplo leque de entendimentos a respeito do Direito Sanitário e mais a variedade e complexidade de situações que envolvem a prestação de serviços de saúde à população relevam a importância do seu ensino e a formação de profissionais especializados para lidar com o tema.

Os poucos cursos oferecidos atualmente no Brasil se devem a iniciativas isoladas de algumas entidades, geralmente, em atendimento a demandas institucionais. Não há uma orientação geral a indicar as demandas da sociedade, currículo mínimo e carga horária. Talvez por sua essência, o tema Direito Sanitário está inserido basicamente na área ou em programas da saúde e não no campo do Direito.

Aith (8) defende que

O estudo do Direito Sanitário, embora esteja situado no âmbito da ciência jurídica, exige uma abordagem multidisciplinar capaz de compreender, na complexidade das sociedades modernas, como é que se processa a tradução, pelo Direito, dos anseios sociais relacionados com a proteção, promoção e recuperação da saúde.

Para Dallari (9),

O ensino do Direito Sanitário, compreendida a evolução conceitual da saúde, implicará seu exame enquanto direito individual, enfatizando, por exemplo, as regras do contrato entre o médico e o paciente, não se esquecendo, contudo, de examiná-la enquanto direito coletivo. [...] O Direito Sanitário deve estudar também todas as normas jurídicas de planejamento da saúde, condicionantes importantes do nível de saúde [...] Deve, portanto, incluir áreas como: Introdução à Filosofia e Sociologia do Direito Sanitário; Organização Jurídica da Administração Sanitária; Direito Penal Sanitário; Direito dos Serviços de Saúde; Direito do Planejamento Sanitário; Direito Previdenciário Sanitário; Direito Internacional Sanitário; Ética Sanitária; Polícia Sanitária; e Direito Sanitário Comparado.

O autor sugere, ainda, que esses temas necessitam de magistério especializado, professores com experiência na área da saúde e do direito, mas ressalva que esse profissional é raro no Brasil e urge formá-lo.

Embora esse alerta de Dallari tenha sido feito em 1988, decorridos mais de 25 anos constata-se que houve avanços, mas ainda há carência destes profissionais especializados, de escolas e cursos de formação em Direito Sanitário e, pode-se acrescentar, faltam mais debates e definições sobre o currículo dos cursos de especialização.

\section{Objetivos}


Na tentativa de esboçar um panorama do ensino especializado do Direito Sanitário no Brasil, desenvolveu-se o presente trabalho com o objetivo de identificar a oferta de cursos de Direito Sanitário, em nível de pós-graduação, em instituições federais de ensino superior do Brasil e em outras instituições que se dedicam à pesquisa e ao ensino dessa área de conhecimento. Buscou-se também identificar como estão distribuídas regionalmente essas instituições e em que área de conhecimento (Saúde/Direito) os cursos estão inseridos.

\section{Metodologia}

O trabalho compreendeu a leitura crítica de conhecimentos estruturados sobre Direito Sanitário e o levantamento de dados e informações junto às instituições de ensino superior, com o propósito geral de saber como o Direito Sanitário é tratado e ensinado nesses estabelecimentos educacionais, com ênfase na pós-graduação. Cursos de graduação não foram incluídos no levantamento.

A metodologia utilizada foi de caráter exploratório, descritivo, analítico. Foi feito levantamento de informações, no período de setembro de 2014 a janeiro de 2015, por intermédio de correio eletrônico (e-mail), telefones e consultas nos sítios eletrônicos (websites) das universidades públicas federais do Brasil e de outras instituições que se dedicam à pesquisa e ao ensino do Direito Sanitário, tais como: Programa de Direito Sanitário (PRODISA), Rede Ibero-Americana de Direito Sanitário, Associação Brasileira de Pós-graduação em Saúde Coletiva (ABRASCO), Centro Brasileiro de Estudos de Saúde (CEBES), Escola de Saúde Pública do Estado de Minas Gerais (ESP-MG), Escola de Saúde Pública do Rio Grande do Sul (ESP-RS), Instituto de Saúde Coletiva (ICS-UFBA), Faculdade de Saúde Pública da Universidade de São Paulo (FSP-USP), Instituto de Direito Sanitário Aplicado (IDISA), Centro de Estudos e Pesquisas de Direito Sanitário (CEPEDISA) e Biblioteca Virtual em Saúde (BVS). Também foi realizada pesquisa na base de dados da Scientific Eletronic Library Online (Scielo) e Google Acadêmico.

Em todas as consultas e levantamentos foram empregados os seguintes descritores:

Direito Sanitário; Curso de Direito Sanitário; Curso de Direito Sanitário e Saúde; Curso de Especialização em Direito Sanitário; Curso de Especialização em Saúde Coletiva; Curso de Especialização em Saúde Pública; Curso de Pós-graduação em Direito Sanitário; Curso de Pós-graduação em Direito e Saúde. 
As informações e os dados coletados foram reunidos e sistematizados de modo a permitir saber quantas e quais instituições oferecem cursos de especialização em Direito Sanitário no Brasil, se elas são públicas ou privadas, onde estão localizadas e se os cursos que oferecem são abertos à sociedade ou restritos, se estão inseridos na área de direito ou na área de saúde, qual a carga horária e a modalidade do ensino (se presencial, semipresencial ou a distância).

\section{Resultados e discussão}

Os dados e informações levantados possibilitaram a revelação de uma radiografia pouco animadora quanto à situação do ensino especializado (pós-graduação) do Direito Sanitário no Brasil, ante as demandas e necessidades da população brasileira e os pleitos que fluem para os tribunais, sobrecarregando os poucos advogados e magistrados versados no assunto.

Nenhuma das mais de sessenta universidades públicas federais brasileiras oferece curso de pós-graduação em Direito Sanitário. Duas delas, a Universidade de Brasília e a Universidade Federal do Rio de Janeiro, mantêm dois cursos de pós-graduação, stricto sensu, em nível de mestrado e doutorado, em que é lecionada a disciplina Direito Sanitário, mas sem relação propriamente com a área do direito.

A lacuna existente nas universidades públicas federais é preenchida por outras instituições de ensino, públicas e privadas, conforme a tabela 1. Essas instituições oferecem diversas modalidades de curso de pós-graduação em Direito Sanitário, porém todos os cursos são na área de saúde pública, nenhum na área de direito. E nenhuma instituição tem atuação nas regiões Norte e Nordeste. Uma dessas instituições, organizada como consórcio interinstitucional teve, como público exclusivo, procuradores públicos federais, membros do Ministério Público e da magistratura federal de todo o País, com o curso inteiramente a distância. O foco dessa instituição foi a preparação de indivíduos para atuarem na resolução de questões que envolvam interesses no âmbito da saúde.

No estado de São Paulo, funcionam o Centro de Pesquisas em Direito Sanitário (CEPEDISA), localizado na capital, e o Instituto de Direito Sanitário Aplicado (IDISA), localizado em Campinas (Tabela 1). O CEPEDISA, conforme registra Martini (10), foi a primeira instituição brasileira a formar profissionais em Direito Sanitário no Brasil. Trata-se 
de uma sociedade científica sem fins lucrativos de apoio à Faculdade de Saúde Pública da Universidade de São Paulo (USP).

O CEPEDISA foi fundado em 1988 e formou grande parte dos pesquisadores e professores de Direito Sanitário e é hoje referência internacional nessa área. A instituição ofereceu regularmente, de dois em dois anos, desde 1989, curso de especialização em Direito Sanitário para graduados das áreas de saúde e Direito, com carga horária de 450 h/a. O curso deixou de ser ofertado por falta de recursos financeiros. Sua última edição foi em 2012. Era ministrado em parceria com o Núcleo de Pesquisa em Direito Sanitário (NEPDISA) da USP (informações verbais). ${ }^{2}$ A USP, contudo, por intermédio da sua Faculdade de Saúde Pública, oferece mestrado e doutorado em Saúde Pública em que é lecionada a disciplina Direito Sanitário (11).

Tabela 1 - Oferta de cursos de pós-graduação em Direito Sanitário em instituições públicas e privadas da área de saúde do Brasil. Janeiro, 2015.

\begin{tabular}{llll}
\hline Instituição & Curso & Localização & Modalidade \\
\hline
\end{tabular}

2 Informações fornecidas pelo CEPEDISA, e por Fábio Corrêa, do Setor de Cursos da USP. 


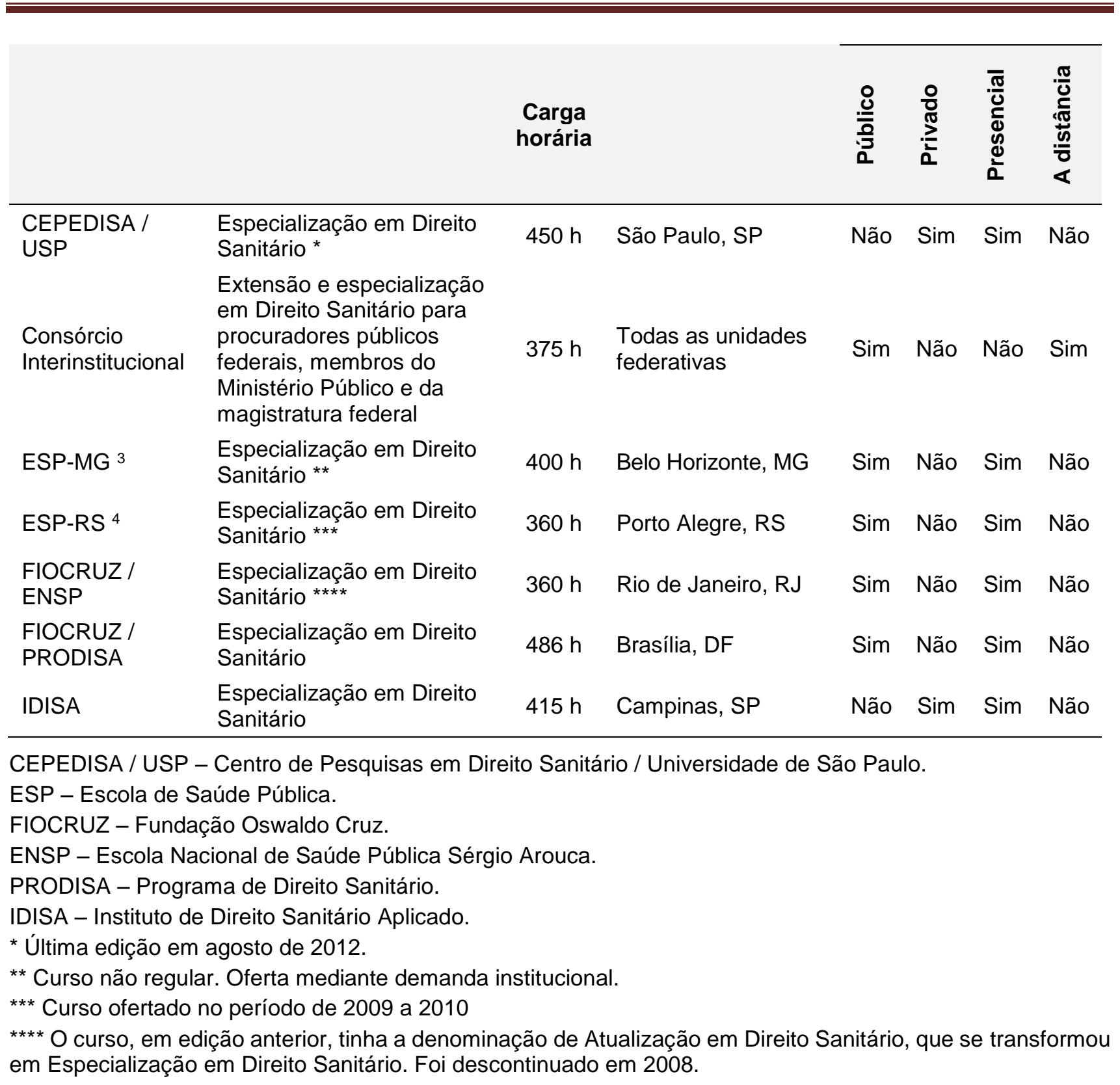

Fontes: CEPEDISA (20150), IDISA (2015), FIOCRUZ (2015), PRODISA (2015), ENSP (2015).

O IDISA é uma instituição privada que oferece regularmente um curso de especialização em Direito Sanitário com duração de 415 horas (Tabela 1). Os primeiros cursos de Direito Sanitário do IDISA foram certificados pela Universidade de Campinas (Unicamp) e atualmente são certificados pelo Hospital Sírio Libanês, como informa o próprio Instituto (12).

\footnotetext{
${ }^{3}$ Informação pessoal, via correio eletrônico (e-mail).

${ }^{4}$ Informação pessoal, via correio eletrônico (e-mail).
} 
Os cursos oferecidos no estado de São Paulo pelo CEPEDISA e IDISA não são gratuitos; cada participante é responsável pelo seu próprio custeio, podendo habilitar-se a bolsa de estudo. Ainda assim, dada a escassez de oferta, os interessados têm de passar por processo seletivo.

Nas escolas de saúde pública (ESP) de Minas Gerais e do Rio Grande do Sul, o curso de pós-graduação em Direito Sanitário é destinado a servidores públicos estaduais de nível superior que atuam no sistema Saúde, mediante demanda institucional. Em Minas Gerais, um curso para servidores públicos do judiciário foi realizado pela ESP-MG em parceria com a Escola Judicial Desembargador Edésio Fernandes (EJEF) e o Tribunal de Justiça do Estado (TJEMG).

A Escola Nacional de Saúde Pública (ENSP) foi criada em 1954, pela União. Atualmente denominada Escola Nacional de Saúde Pública Sérgio Arouca, é vinculada à Fundação Oswaldo Cruz (Fiocruz) e considerada a maior escola de saúde pública da América do Sul. No início dos anos 2000, a ENSP, no âmbito do seu Programa Direito e Saúde, começou a oferecer um Curso de Atualização em Direito Sanitário, que a partir de 2004 foi transformado em Curso de Especialização em Direito Sanitário, voltado para a capacitação de profissionais da saúde e do direito. Esse curso foi descontinuado no ano de 2008, com a reformulação do Programa e a desvinculação da disciplina Direito Sanitário, substituída pela disciplina Direito e Saúde (13).

A ENSP oferece também cursos de pós-graduação (mestrado e doutorado) em Saúde Pública, Meio Ambiente e Epidemiologia, nos quais a disciplina Direito Sanitário é ministrada com carga horária de $30 \mathrm{~h} / \mathrm{a}$ (Ibidem).

A Fiocruz é vinculada ao Ministério da Saúde e mantém um Programa de Direito Sanitário (PRODISA) desde o ano 2000. Por meio desse programa, a Fiocruz protagonizou, em parceria com a Escola Nacional de Saúde Pública Sérgio Arouca e a Secretaria de Saúde do Distrito Federal, o I curso de Especialização em Direito Sanitário para inspetores de vigilância sanitária do Distrito Federal, realizado em Brasília, em 2003. Ainda hoje, esse curso é regularmente oferecido. O PRODISA atua em várias frentes - ensino, pesquisa e extensão -, edita publicações, promove fóruns de discussão e ações sobre o tema e tem contribuído para difundir conhecimentos sobre Direito Sanitário e para ampliar o debate acerca do direito à saúde pública (14) (15). 
$\mathrm{Na}$ Bahia, embora não se tenha encontrado registro de curso especializado de Direito Sanitário oferecido por instituição local, o Instituto de Saúde Coletiva (ISC) da Universidade Federal da Bahia (UFBA), com sede em Salvador, oferece curso de mestrado e doutorado em vigilância sanitária onde é lecionada a disciplina Fundamentos do Direito Sanitário, com carga horária de $34 \mathrm{~h} / \mathrm{a}$ a $38 \mathrm{~h} / \mathrm{a}$ (informação pessoal) ${ }^{5}$.

Chama particularmente atenção na tabela 1 a diferença da carga horária entre as instituições, variando de 360 horas a 486 horas, uma diferença, portanto, de mais de $25 \%$ (vinte e cinco por cento). Não foram cotejadas as ementas curriculares dos cursos para explicar essa diferença.

$\mathrm{Na}$ rede federal de educação profissional e tecnológica, composta de 89 unidades de ensino, distribuídas em várias localidades do País, não há oferta de curso de pósgraduação em Direito Sanitário nem é oferecida a disciplina em qualquer outro curso, conforme o levantamento realizado. Essas instituições conferem título de ensino de nível superior reconhecido pelo Ministério da Educação e estão concentradas na Região Sudeste, com 31 unidades. Várias oferecem curso de pós-graduação, mestrado e doutorado, mas parece não se interessarem em investir em Direito Sanitário, uma área de relevante interesse social.

Pode-se afirmar, com base nos dados e informações levantadas, que o ensino do Direito Sanitário no Brasil não tem ainda a relevância que o tema merece, o que deixa a população brasileira vulnerável diante das múltiplas questões e demandas a envolver a saúde pública e dos poucos profissionais aptos a lidar com o assunto.

As demandas judiciais envolvendo a assistência à saúde, particularmente no que diz respeito a tratamentos e medicamentos prescritos pela classe médica, e de eficácia questionada, que dependem da aprovação da Agência de Vigilância Sanitária (Anvisa), têm suscitado contendas em tribunais, que, por sua vez, se veem com dificuldades para fundamentar sentenças.

Martini (10) destaca que as demandas na área de saúde vêm crescendo no Brasil e no mundo, mas a capacitação de profissionais especializados em direito à saúde é incipiente e não segue o mesmo ritmo. As demandas crescentes, observa a autora, são reveladoras da fragilidade das políticas públicas.

\footnotetext{
${ }^{5}$ Informação fornecida por Ana Cristina Souto, da coordenação do curso de pós-graduação do ISC/UFBA.
} 
Essa limitação é nitidamente reconhecida até na alta magistratura do País. Foi essa situação que levou o Conselho Nacional de Justiça (CNJ) a editar, em 30 de março de 2010, a Recomendação $n^{\circ} 31$, que aconselha os tribunais a adotar medidas que melhor subsidiem os operadores do direito na solução das demandas. Entre outras medidas, o CNJ recomenda que os tribunais busquem o apoio técnico de médicos e farmacêuticos para auxiliar a magistratura na formação de juízo de valor na apreciação das demandas e que incluam o Direito Sanitário como matéria no programa de direito administrativo dos concursos para ingresso na magistratura (16).

Importante ressaltar que o CNJ também recomenda que as escolas de magistratura incluam o Direito Sanitário nos programas dos cursos de formação e aperfeiçoamento de magistrados. A iniciativa do CNJ deveria servir de incentivo para que as escolas públicas federais, e mesmo estaduais e privadas, e os cursos de direito em geral, deem mais atenção ao Direito Sanitário e ampliem a oferta de cursos sobre a matéria, sobretudo na pósgraduação.

Aparentemente não há óbices para a regulamentação e inserção de cursos de pósgraduação nas faculdades de direito das universidades públicas federais. A relação com outros ramos do direito parece evidente, e as particularidades são próprias de cada ramo.

Embora o Direito Sanitário tenha o seu foco nas ações que envolvem a saúde, sua essência é fundamentalmente jurídica. Ele se nutre e ao mesmo tempo alimenta saberes de várias outras áreas de conhecimento, mas é sobretudo na ciência do direito que ele robustece a sua natureza e amplia o seu alcance. As ementas curriculares dos cursos de Direito Sanitário, ainda que estes se encontrem inseridos principalmente nos programas de escolas preparatórias de profissionais de saúde, revelam claramente que a formação é predominantemente jurídica.

Mello (17) entende que há uma disciplina jurídica autônoma quando corresponde a um conjunto sistematizado de princípios e normas que lhe dão identidade, diferenciando-as das demais ramificações do direito.

No âmbito internacional, o Direito Sanitário vem sendo ensinado e mantido nos cursos de pós-graduação em todos os países europeus, em especial na Itália e na França, onde geralmente estão inseridos nas escolas de direito. Na América do Norte, é ensinado em várias universidades dos Estados Unidos, mormente em escolas de saúde pública (9). 
Na América Latina, o ensino do Direito Sanitário vem sendo inserido de forma lenta e gradual nos cursos de pós-graduação, particularmente na Argentina e no Brasil.

Ressalta-se que já houve uma importante tentativa de implantação da disciplina de Direito Sanitário no currículo mínimo dos cursos de direito no Brasil. A iniciativa foi do deputado Henrique Brito, que, em 1979, propôs projeto de lei (PL 1104/1979) que instituía, em caráter obrigatório, a disciplina Direito Sanitário no currículo mínimo dos cursos de Direito de todo o País (18). Na justificativa do projeto de lei foi citado o crescente interesse dos países, em diferentes etapas de desenvolvimento econômico, pelo direito à saúde.

O projeto foi embasado por uma ampla abordagem da necessidade de inclusão das temáticas correlatas à saúde em diversos ciclos do processo educacional brasileiro. De acordo com o autor do projeto, dada a legislação sobre o tema e a importância do sanitarismo para o Brasil, somente a instituição de uma disciplina específica poderia dotar os bacharéis em direito de conhecimentos suficientes sobre o assunto, o que repercutiria em melhor desempenho profissional.

Mesmo reconhecendo a constitucionalidade e a boa técnica legislativa do projeto de lei, a Comissão de Educação e Cultura da Câmara Federal o rejeitou, argumentando que a ação específica não era capaz de impactar, por si só, na saúde da população. Passados trinta e seis anos desde a apresentação do projeto de lei do deputado Henrique Brito, a realidade mostra que o assunto não foi devidamente analisado pelo parlamento e é inexplicável que o debate não tenha sido retomado pelos legisladores, ainda que o tema seja constantemente objeto de discussão em congressos e reuniões de especialistas em saúde e de educadores.

Mas mesmo nas reuniões e congressos de especialistas, o assunto ainda carece de produzir mais resultados práticos. No presente estudo, foi identificado que nas universidades públicas federais do Brasil o ensino do Direito Sanitário como matéria regular na estrutura curricular não existe.

Como se pode inferir do quadro de realidade exposto, o ensino do Direito Sanitário no Brasil se deve a iniciativas isoladas e insuficientes ante o panorama de necessidades. Não é um assunto que tem merecido ações articuladas ou programas integrados. Seria alvissareiro que tais iniciativas fossem multiplicadas e que ações mais efetivas nas esferas de poder fornecessem o ordenamento e o suporte necessários. Certamente ajudariam a 
enriquecer e a fortalecer o Sistema Único de Saúde (SUS), ampliando os benefícios à saúde da população brasileira.

O direito universal à saúde no Brasil foi conquistado com a Constituição de 1988, e já existe todo um arcabouço jurídico para dar sustentação à garantia desse direito, mas a população em geral pouco sente os efeitos práticos dessa conquista, convivendo com situações até mesmo anárquicas na área de saúde. A questão envolve muitas variáveis e múltiplas frentes de ação, com diferentes graus de complexidade. O aumento da oferta de cursos especializados em Direito Sanitário pelas universidades públicas federais ou, dito de outra forma, a formação especializada de profissionais aptos a lidar com a questão da saúde pública, é uma pequena faceta dessa questão, mas poderia contribuir sobremaneira para diminuir a dívida social do Estado para com a sociedade, principalmente com os mais desassistidos.

\section{Conclusão}

O ensino do Direito Sanitário não faz parte da estrutura curricular dos cursos de pósgraduação em direito das universidades públicas federais e só aos poucos vem sendo incorporado por algumas instituições de saúde pública, em lugares isolados do País. De modo geral, a ênfase da grade disciplinar dos cursos oferecidos é o direito e não a saúde, embora os cursos estejam inseridos na área de saúde, o que revela uma aparente incoerência.

O Direito Sanitário consolida-se como fenômeno jurídico-social, tendo como fundamentos a saúde e o direito. Carece ainda, no entanto, de mais atenção e de ser compreendido de maneira global. No Brasil, deriva naturalmente da forma como saúde e direito se relacionam, com ampla gama de peculiaridades em que o tema saúde é enfrentado pela população e é abordado por diferentes instâncias em cada unidade da federação brasileira.

Nesse campo de conhecimento o Estado pode encontrar o saber apropriado para balizar políticas públicas de saúde que contemplem a prevenção e o combate a doenças e os operadores do direito podem se nutrir para elucidar questões jurídicas que condicionam condutas humanas relacionadas à saúde e ao bem-estar da população. O Direito Sanitário 
reúne princípios que ajudam a nortear diretrizes e competências que convirjam para o fortalecimento do sistema de saúde, mas falta reconhecimento de sua importância.

Enquanto esse ramo do direito não for devidamente reconhecido e regulamentado e ganhar mais atenção, os operadores do direito, os cidadãos e as instituições valem-se do arcabouço jurídico-institucional disponível sobre o direito à saúde e sobre a legislação sanitária nacional e internacional, nem sempre suficiente para a resolução de situações de conflito e aprimoramento de mecanismos que possam contribuir para o bem-estar das pessoas.

Para que toda a população conquiste e se beneficie plenamente de um sistema de saúde plural, justo e eficiente, é preciso avançar na fundamentação e difusão dos direitos à saúde. E uma das ações indispensáveis nesse sentido é a ampliação da oferta de cursos de capacitação e especialização em Direito Sanitário, de modo a ampliar a discussão, a compreensão e a aplicação do saber jurídico em torno do tema.

Como apresentado neste trabalho, embora o Direito Sanitário seja fundamentado no saber jurídico, a capacitação no nível de pós-graduação é oferecida por instituições cujo foco principal é a saúde e por outras de formação geral. A inserção de cursos de pós-graduação em Direito Sanitário nas escolas de direito traria ganhos sociais? A resposta a essa questão deve merecer mais debates na sociedade. Parece claro que o direito não acompanhou a evolução e o dinamismo das ciências de saúde, deixando uma lacuna entre o direito e a saúde. Este trabalho constatou uma situação que está a merecer mais reflexão, incentivo e pesquisas.

\section{Referências}

1 - Brasil. Constituição da República Federativa do Brasil. Brasília: Senado Federal, 2013. [Acesso em 5 jan 2015]. Disponível em: http://www.senado.gov.br/legislacao/const/con1988/CON1988 05.10.1988.

2 - Brasil. Lei n 8.080, de 19 de setembro de 1990. Dispõe sobre as condições para promoção, proteção e recuperação da saúde, a organização e o funcionamento dos serviços correspondentes e dá outras providências. (Lei Orgânica da Saúde). [Acesso em 7 fev 2015]. Disponível em: <http://www2.camara.leg.br/legin/fed/lei/1990/lei-8080-19setembro-1990-365093-normaatualizada-pl.pdf 
3 - Dallari SG. Direito Sanitário. In: Brasil. Ministério da Saúde. Direito sanitário e saúde pública. Coletânea de Textos. Brasília: Ministério da Saúde, 1:48. 2003. [Acesso em 18 set. 2014]. Disponível em: http://bvsms.saude.gov.br/bvs/publicacoes/direito san v1.pdf.

4 - Canut L. Uma breve introdução ao SUS para a compreensão do direito à saúde no Brasil. Revista de Direitos Fundamentais e Democracia. 2012 [Acesso em 22 out 2014], 12(12): 186-214. Disponível em:

http://revistaeletronicardfd.unibrasil.com.br/index.php/rdfd/article/view/186.

5 - Delduque MC. Las rupturas cosmológicas, antropológicas y epistemológicas hasta las ciencias multidisciplinarias: el derecho sanitario y el derecho medico. Em: Conferência de Direito Sanitário, I, fev. 2012. Porto Príncipe, Haiti. (Anais no prelo)

6 - Aith FMA et al. Organizadores. Direito sanitário: saúde e direito, um diálogo possível. Belo Horizonte: ESP-MG, 2010. [Acesso em 2 out. 2014]. Disponível em: http://www.esp.mg.gov.br/wp-content/uploads/2012/06/Direito-sanitario_Final.pdf

7 - Dias HP. Direito Sanitário. 2003. [Acesso em 14 out 2014]. Disponível em: http://www.anvisa.gov.br/divulga/artigos/artigo direito sanitario.pdf

8 - Aith FMA. Teoria geral do Direito Sanitário brasileiro. [Tese]. São Paulo, Universidade de São Paulo, Faculdade de Saúde Pública; 2006. [Acesso em 2 out 2014]. Disponível em: http://www.teses.usp.br/teses/disponiveis/6/6135/tde-23102006-144712/pt-br.php.

9 - Dallari SG. Uma nova disciplina: o Direito Sanitário. Rev. Saúde Pública. 1988. [Acesso em 18 set 2014], 22(4): 327-334. Disponível em:

http://www.scielo.br/scielo.php?script=sci arttext\&pid=S0034-

89101988000400008\&lng=en\&nrm=iso.

10 - Martini SR. Formação em Direito Sanitário: a experiência brasileira. In: Congreso Iberoamericano de Derecho Sanitario, IV y Seminario Internacional de Derecho Sanitario, II, 2014. Costa Rica: Facultad de Derecho, Red Iberoamericana de Derecho Sanitario, 2014.

11 - CEPEDISA. Centro de Estudos e Pesquisas de Direito Sanitário. USP. Cepedisa. [Acesso em 5 jan 2015]. Disponível em: http://hygeia.fsp.usp.br/cepedisa/quemsomos.htm

12 - IDISA. Instituto de Direito Sanitário Aplicado. Direito Sanitário. [Acesso em 5 jan 2015]. Disponível em: http://www.idisa.org.br/site/pesquisa pesquisa 0 0.html.

13 - Escola Nacional de Saúde Pública (ENSP). Fiocruz. Linha do tempo. [Acesso em 5 jan. 2015] Disponível em: http://www.ensp.fiocruz.br/portal-ensp/linha-do-tempo.

14 - Fiocruz Brasília. Programa de Direito Sanitário (PRODISA). [Acesso em 5 jan 2015]. Disponível em: http://www.fiocruzbrasilia.fiocruz.br/node/42.

15 - PRODISA. Programa de Direito Sanitário. Fiocruz. Uma trajetória de conquista e reconhecimento do Direito Sanitário. [Acesso em 5 jan 2015]. Disponível em:

http://prodisa.fiocruz.br/?page id=5. 
16 - Brasil. Conselho Nacional de Justiça (CNJ). Recomendação no 31, de 30 de março de 2010. [Acesso em 5 jan. 2015]. Disponível em: <http://www.cnj.jus.br/atosadministrativos/atos-da-presidencia/322-recomendacoes-do-conselho/12113recomendacao-no-31-de-30-de-marco-de-2010

17 - Mello CAB. Curso de direito administrativo. São Paulo: Ed. Malheiros; 2002.

18 - Brasil. PL 1104/1979. Projeto de Lei $n^{\circ} 1179$, de $1^{\circ}$ de junho de 1979. Institui a disciplina Direito Sanitário no currículo mínimo dos cursos de direito de todo o país. [on line]. Autor: Deputado Henrique Brito. [Acesso em 5 jan 2015]. Disponível em: $<$ http://www.camara.gov.br/proposicoesWeb/fichadetramitacao?idProposicao=187404 